\title{
THE IMMATURE STAGES OF BORIOMYIA FIDELIS (BANKS) WITH TAXONOMIC NOTES ON THE AFFINITIES OF THE GENUS BORIOMYIA (NEUROPTERA:HEMEROBIIDAE)
}

\author{
By Ellis G. MacLeod \\ University of Maryland \\ College Park, Maryland
}

\section{Introduction}

The genus Boriomyia Banks, I904 (sensu Killington, 1937, Carpenter, I940; nec Banks, I905, Tjeder, I94I, et seq.) is known only from the Nearctic Region where it is represented by the type species B. fidelis (Banks) and by B. speciosa (Banks). To date the biology of the immature stages of neither of these species has been elucidated. $B$. fidelis has been taken with fair frequency in the middle Atlantic states and the author has made several attempts to rear this interesting hemerobiid; however, it has only been recently that this effort has met with any success. Although this study represents a portion of a more general investigation of the morphology and ecology of the immature stages of the Nearctic Neuroptera, it seems desirable to publish these notes at this time because of their bearing on the question of the relationship of Boriomyia to the other genera of the Hemerobiidae.

The writer wishes to express his gratitude to Mr. Ivan Huber of the Food and Drug Administration, Department of Health, Education and Welfare, who supplied the author with several living females, including the all-important specimens whose offspring form the basis for this account.

\section{Methods}

The immature stages which were utilized in this study were derived from three females collected in College Park and Greenbelt, Prince Georges Co., Md., in 1956 and 1958. After rearing and preservation, thirty-seven first instar larvae, ten second instar larvae, eighteen third instar larvae and two pupae were available for morphological investigations. Although this species can be identified from either sex of the adult with good reliability, the best taxonomic characters are found in the genitalia of the male. Accordingly, threc pupae, the offspring of a single female, were allowed to transform and two of these produced males by which the initial identification of one of the original females was confirmed. These identifications were made by the writer utilizing the key of Carpenter (1940). 
Past experience with numerous types of Neuroptera has indicated that when eggs can be obtained from field-collected females, these eggs are fertile. The usual procedure for inducing oviposition by such females has been to confine the insect in some suitable container. Thus Smith ( I922) was quite successful in securing eggs from females of various Nearctic species of Chrysopa by placing them in lampchimney cages over growing, aphid-infested plants, the aphids serving as food for the female and possibly also as an oviposition stimulus. Killington ( I937) utilized much the same procedure in obtaining eggs from many species of British hemerobiids.

Although this method was tried by the present writer, the inspection of so large a volume for the infrequent eggs supplied by the females of $B$. fidelis proved difficult. In addition, the broadly oval wings of this species with their numerous macrotrichiae render the insect somewhat clumsy and almost any confined space serves to trap the female, the leaf axils of the plants serving especially well in this respect.

A more satisfactory arrangement was found by confining the females individually in $75 \times 25 \mathrm{~mm}$. cotton-stoppered glass vials. Humidity was supplied from a small pleget of cotton, dampened with a solution of sucrose and water which was placed in the bottom of the vial. To obviate the possibility of the female becoming stuck to the wet cotton, a cardboard partition was placed between the damp cotton and the female and this was removed only for a short time each day to permit the female to drink. Small nymphs of the aphid Macrosiphum liriodendri (Monell) collected from nearby tulip trees (Liriodendron tulipifera (L.)) were supplied on a small piece of leaf daily.

Eggs, which were invariably laid on the cotton plug of the oviposition vial, were removed as soon as detected and placed singly in $40 \times 13 \mathrm{~mm}$. cotton-stoppered shell vials. Larvae were supplied each day with nymphs of the same aphid as was fed to the adults. This food was introduced into the vial on a piece of fresh leaf which probably served to maintain a reasonable humidity although no attempt was made to control or record this variable. Small wads of damp cotton were placed in the vials after the cocoons had been spun in order to prevent exccssive dryness; however, these were not placed in vials with larvae in order to eliminate any possibility of the larvae becoming trapped and drowning. These rearings were carricd out in a room open to the usual fluctuations in the summer temperatures 
which occurred during the periods of this study (June 25-August 8, I956, and June I9-July I8, I958).

Color notes were made from microscopic observations of living larvae and these were supplemented by color photographs taken of freshly killed larvae. The drawings of Plates 5 and 6 were prepared by the author from these notes, from material fixed in Peterson's KAAD fluid (see Peterson, I953, for details of preparation) and stored in alcohol, and from the examination of cleared specimens in temporary glycerine mounts with a binocular dissecting microscope and with a phase-contrast compound microscope. All measurements were made with an ocular micrometer calibrated with a stage micrometer. All indices of dispersion given in this paper are standard errors of the mean.

\section{Description of The Developmental Stages}

Oviposition and embryonic development - The three females used in this study were confined for periods of nine, fifteen and twenty-two days, during which times a total of ninety-four eggs was deposited. These were produced in a series of small lots which, with one exception, contained between one and eight eggs $(\bar{x}=3.53 \pm 0.53$ eggs $/$ lot). In a single instance a freshly caught female, whose abdomen was noted to be tremendously swollen with eggs, laid twenty-seven eggs during her first twenty-four hours of confinement. Subsequent to this, however, the egg production of this female fell within the limits noted above. In all cases oviposition occurred at night and was never observed by the writer.

In addition to the ninety-four eggs produced by these females, the remains of an undetermined number of other eggs were noted which had, apparently, been partially consumed by the females. Six of the ninety-four eggs regarded as normal may also have been damaged by one of the females as these were slightly distorted in shape when first seen and none of them showed any signs of embryonic development. Three additional eggs although seemingly normal in all respects also failed to show any indication of development. Of the eighty-five eggs which showed apparent normal development, two failed to hatch.

Egg - Approximately ellipsoid in shape, distinctly flattened on surface attached to substratum. Color, a pale greyish-yellow, becom-

Explanation of Plate 5

Fig. 1. Facies of head capsule of first instar larva, dorsal view.

FIg. 2. Head capsule and prothoracic "collar" of third instar larva, dorsal view. 

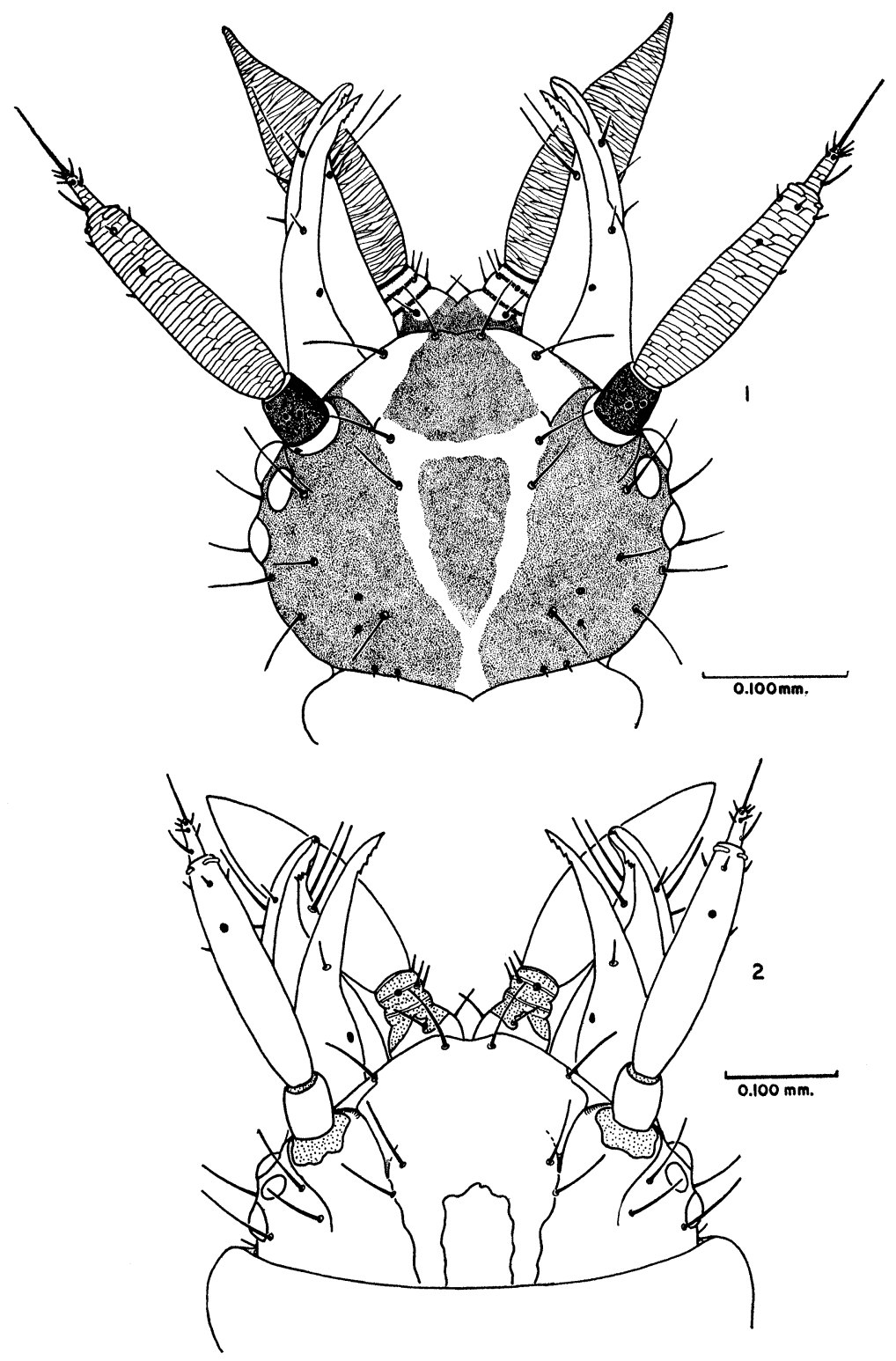

MACLEOD - BORIOMYIA 
ing greyish-brown as embryo develops. Micropyle sessile, flattened, chalk-white; a minute depression in center. Chorion, apparently smooth, but showing a minutely granulate texture at a magnification of $60 X$ giving the impression of finely frosted glass. At higher magnifications an irregular imprinted pattern visible, attributed to the pressure of follicular cells of ovary by Killington (1946). Minute elevations and tubercles of chorion reported for several other hemerobiid genera by Killington (1936) lacking in B. fidelis. Size of a single unhatched egg: length $-0.7752 \mathrm{~mm}$., greatest width -0.3420 $\mathrm{mm}$.

The eyes of the embryo become visible through the chorion after four days, while hatching takes place after about seven and one-half days of development $(\overline{\mathrm{x}}=7.6 \pm 0 . \mathrm{I}$ days, $\mathrm{N}=70)$. As with other Neuroptera, emergence from the chorion is assisted by an eggburster (figs. 5, 6) which forms a longitudinal ridge-like projection from the embryonic cuticle in the region of the clypeus. In a series of eggbursters derived from seven siblings which were studied in detail, the number of small teeth along the distal margin of the blade was found to vary between twenty-two and twenty-nine $(\bar{x}=25.0$ $\pm 0.9)$. The two extremes are figured in figs. 5 and 6.

First instar larva (figs. I, 3) - Head capsule ellipsoid, prominent, as wide as widest part of body; of a uniform grey color dorsally, this interrupted medially by a Y-shaped ecdysial cleavage line passing down to clypeal margins just medial to bases of jaws on either side; anterior, diverging arms of cleavage line cross connected by transverse area of pale cuticula at level of anterior tentorial pits delimiting a proximal frontal area and a distal clypeal area. Ocular area of head capsule antero-lateral, consisting of three, clear corneal swellings. Anterior two corneae each with one dark ommitidial element beneath; three additional ommatidiae visible beneath posterior cornea. Latero-ventral surface of head capsule with usual pair of dark fuscous lines; the more dorsal, running between posterior tentorial pit and dorsal articulation of mandible, representing the subgenal sulcus, the more ventral, running from vicinity of posterior tentorial pit to maxillary component of jaw, representing cardo and stipes. Ventral surface of head capsule largely covered with shield-shaped mental region of labium.

Antenna three segmented, short, reaching only to tip of extended jaws. Basal segment dark, fuscous; short, only slightly longer than wide. Second segment comprising most of length of antenna, about five times as long as first segment. Third segment short, peg-like, 
approximately of same length as basal segments; surmounted by a terminal seta slightly longer than segment itself. Distal two segments pale grey, showing usual irregular pattern of annular sclerotizations characteristic of antennae of hemerobiid larvae (fig. I). Jaws slightly curved inwards; pale grey toward base, becoming dark brown for distal one-third of length. Labial palpi three segmented. Basal segment short, slightly wider than long; arising from largely fuscous, mound-like palpigeral swelling on antero-ventral surface of head capsule. Second segment of same shape as first segment. Both of basal two segments braced by a mid-segmental thin, dark, sclerotic ring. Distal segment of palpus elongate, inflated, reaching well beyond tips of jaws when extended forwards. Surface of distal palpal segment covered with same irregular pattern of annular sclerotizations found on distal two segments of antenna. Base of distal palpal segment braced by a thin fuscous ring.

Thorax-Prothorax with usual three subdivisions. Anterior subsegment short, transverse, forming a collar which overlaps posterior margin of head capsule only slightly. Posterior subsegment of prothorax with spiracle opening on lateral surface. Mesothorax with two subdivisions, metathorax consisting of leg-bearing portion only. Leg-bearing portions of thoracic segments with latero-dorsal sclerites reduced to mere vestiges, easily visible only upon examination of cleared specimens with phase microscope.

Legs largely pale except for thin fuscous sclerotizations partially encircling distal end of each coxa and each femur and proximal margin of each tibia. Pretarsus of all legs with usual clavate empodium extending from between the pretarsal claws.

Abdomen consisting of ten segments; first eight segments membranous, with a spiracle located laterally on each segment. Segment nine with a sclerite covering most of dorsal surface. Tenth abdominal segment largely covered with four small sclerites, one dorsally, one ventrally and one on each side. A pair of eversable pygopods contained within posterior portion of this segment.

Cuticle of thoracic and first eight abdominal segments of unfed larva a light pinkish-purple color through which color of body contents shows through as a light greenish-yellow background. Color of this background changing with the intake of food to an orange hue and then to a dark reddish-orange extending from middle of prothorax to second abdominal segment. Abdominal segments nine and ten pale grey throughout the first larval stadium with their sclerites just visible under a dissecting microscope. Aorta at first only 
faintly visible between anterior prothorax and eighth abdominal segment, toward end of stadium becoming outlined by small isolated patches of developing fat body on either side of aorta. Fat body particularly well-developed in posterior subsegments of pro- and mesothorax.

Duration of first larval stadium $3.4 \pm 0.7$ days $(\mathrm{N}=33)$

Length of unfed first instar larva (measured from clypeal margin of head capsule to posterior margin of dorsal sclerite of tenth abdominal segment) $\mathrm{I} .57 \pm 0.12 \mathrm{~mm} .(\mathrm{N}=6)$

Maximum width of head capsule (measured across ocular areas) -

$$
0.3018 \pm 0.0009 \mathrm{~mm} \text {. ( } \mathrm{N}=7)
$$

Subsequent development of $\mathrm{B}$. fidelis - The head capsules of the second and third instar larvae (fig. 2) are quite similar to each other and differ from that of the first instar larva principally in being slightly wider in proportion to their lengths, which, combined with a lack of the curvature of the lateral margins of the head present in the first instar larva, gives the dorsal aspect of the head capsule a distinctly more quadrate appearance. In addition, the formerly fuscous regions of the clypeal area dorsally and the mental region of the labium ventrally of the first instar larva are pale in the subsequent larval instars so that only the frontal and parietal areas are darkened in these stages. The labial palpi are somewhat less inflated in appearance in the second and third instar larvae although they remain stouter than is usual in this family and reach well beyond the tips of the extended jaws.

The pretarsi of all legs of the second and third instar larvae lack the empodium present in the first instar larva, its place being taken by a delicate, fan-like arolium, arising from the dorsal surface of the pretarsus. Posteriorly, the tergal area of the nineth abdominal segment is no longer covered by a distinct sclcrite in the second and third instar larva.

The body form of the second and particularly the third instar larva (fig. 4) becomes progressively swollen and grub-like with the development of a complex series of projecting lobes on the original segments of the body. The anterior subsegment of the prothorax remains short and collar-like and the head capsule becomes increasingly retracted within this portion of the body, so that although the head can be extended, the usual condition in which to find a living larva is with the 
head withdrawn within the prothorax as far anteriorly as the bases of the antennae.

The body pattern visible to the eye is the result of the interplay between three somewhat variable features. The integument is lightly pigmented by a mottled pattern of a diffuse, purple color which overlies a much darker reddish-purple color due to the gut contents and hemolymph. Between these regions, the rapidly developing fat body creates an intricate series of patches which are nearly pure white in regions where the cuticle is faintly pigmented and which show as darker purple areas where the cuticle is more darkly pigmented. The exact pattern which the larva presents depends largely on the extent of the development of the fat body which gradually fills most of the available space of the hemocoel. One constant feature of this pattern is the presence of two white transverse bands across the body on the posterior subsegments of the prothorax and mesothorax due to the near lack of cuticular pigment in these regions. Ventrally the palpigers consistently include a small portion of the fat body within them which shows through the clear cuticle as a snow-white patch. In a dorsal view of a fully mature third instar larva (fig. 4) the fat body will be seen to have ramified throughout the body leaving only paired lateral "windows", from the posterior margin of the prothorax through the sixth abdominal segment, and the aorta in the dorsal midline through which the darker color of the hemolymph shows through.

A typically hemerobiid cocoon is spun by the third instar larva. This consists of a loose network of silk strands within which is located a more-compact inner cocoon which is, nevertheless, open enough to permit easy observation of the final stages of development. Pupation, metamorphosis and the eclosion of the adult all occur without any apparent cessation of development. The pupa is typical of that of many hemerobiids studied by the writer and, so far as can be ascertained, possesses no prominent features peculiar to Boriomyia. Post first instar development may be summarized as follows:

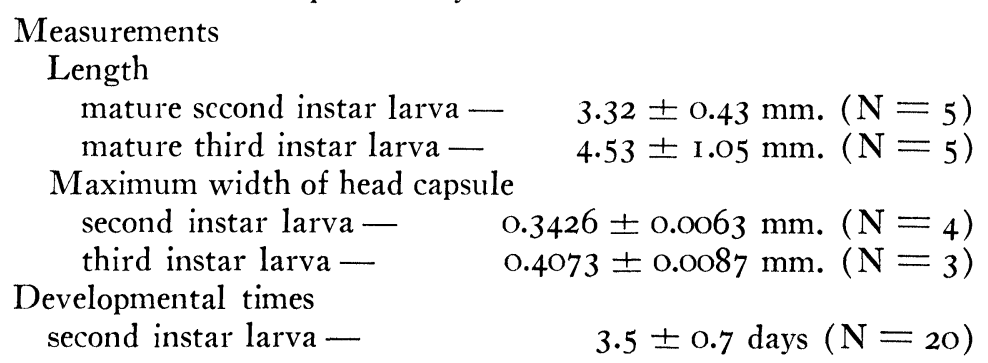




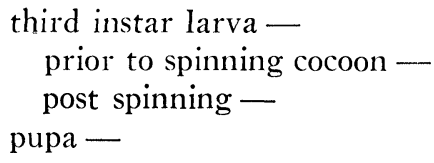

$$
\begin{array}{r}
4.5 \pm 0.1 \text { days }(\mathrm{N}=4) \\
6.9 \pm 0.4 \text { days }(\mathrm{N}=4) \\
10.7 \pm 0.4 \text { days }(\mathrm{N}=3)
\end{array}
$$

Behavioral and ecological notes - The young first instar larva is the only stage which is really active in the sense of seeking out prey. The older first instar larva and particularly the second and third instar larvae tend to remain immobile in some corner of the vial, a favored site for this position being between the cotton plug and the side of the vial. Aphids which move too close to the larvae are seized by a quick upward thrust of the jaws from below. The prey does not seem to be sucked as thoroughly as has been observed to occur with various species of Hemerobius and Micromus with which the author has worked. In these genera the prey is manipulated by the larva until the jaws have probed into every available corner of the body. The larvae of $B$. fidelis seem to simply suck the immediately available fluids of the prey with only incidental movement of the aphid.

One behavioral trait of the adult deserves some comment because of its bearing on the question of the affinities of Boriomyia discussed below. When at rest, the adult consistently assumes a distinctive position by placing the anterior surface of the head flat against the substratum with the antennae directed posteriorly between the legs and neatly clasped by both pairs of palpi. In many respects this position is reminiscent of the death-feigning position which many Neuroptera will assume if startled suddenly by a sharp vibration, although in this case the insect drops to the ground and lies on its side and even though the antennae are directed posteriorly beneath the body, they are not clasped by the palpi.

The natural ecology of this insect remains almost completely unknown as the writer has yet to locate any of the immature stagcs in the field. Of possible interest in terms of the habitat of this species is a collection of three males and two females taken in a short time in an open pine woods near Charleston, S. C. These were captured on April 20, I957, and I am informed by the collectors, Messers. Ivan

Explanation of Plate 6

FIG. 3. First instar larva, dorsal view.

FIG. 4. Mature third instar larva, dorsal view. The latero-dorsal sclerites of the larvae shown in figs. 4 and 5 are depicted as seen by the microscopic examination of cleared specimens. In life these sclerites are nearly invisible.

Figs. 5 and 6. Egg bursters, showing extremes in the number of teeth, lateral view. 


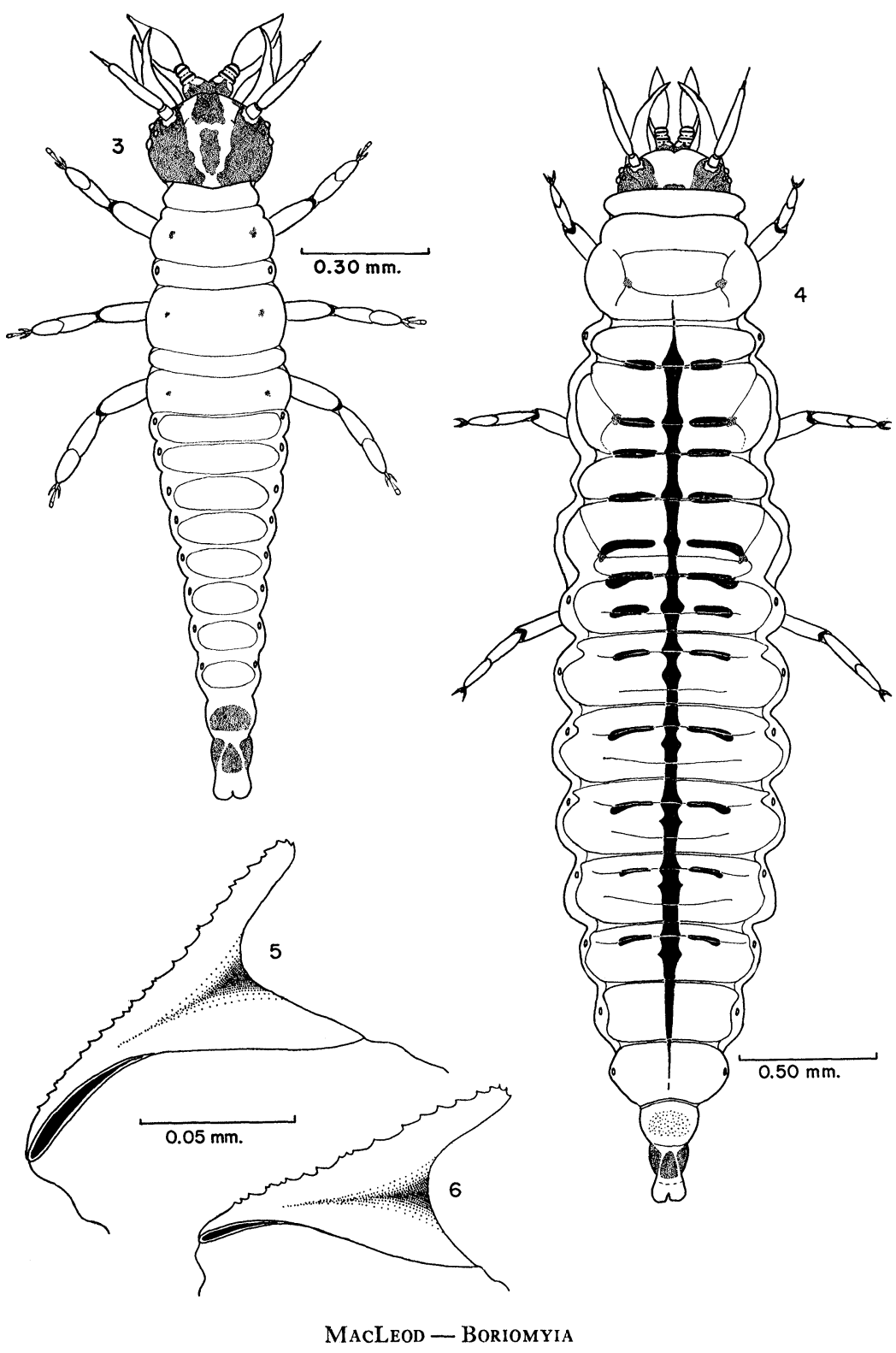


Huber and Paul E. Spiegler, that the insects seemed to be associated with piles of dead branches of yellow pine (Pinus australis Michx.) on the ground.

\section{The Taxonomic Status of Boriomyia}

A series of nomenclatorial mistakes combined with several taxonomic errors in evaluating published descriptions have obscured the true relationships of this genus within the Hemerobiidae. The name Boriomyia appeared for the first time in 1904 when Banks included his previously described species Hemerobius fidelis and H. speciosus under this generic name. A formal description of Boriomyia as a new taxon appeared in I905 in Banks' Revision of the Nearctic Hemerobiidae. In this work, six Nearctic species were included in this genus in addition to $B$. fidelis and $B$. speciosa, one of these, $H$. disjunctus Banks, being designated as the type species. Subsequently additional Nearctic and numerous exotic species were referred to Boriomyia by various workers. In 1930 Banks, recognizing that $B$. fidelis and B. speciosa did not form a homogeneous group with the remainder of the species placed in Boriomyia, erected a new subgenus, Allotomyia, for these two species and subsequently (1935) treated this group as a full genus.

Killington (1937) agreed that the two groups of species recognized by Banks should be separated generically, but pointed out that since the name Boriomyia had been validated in 1904 when it was used in combination with two already-described species, Banks' 1905 designation of $H$. disjunctus as the type of Boriomyia was in violation of the Rules since this species was not included in Boriomyia when this name was originally validated. Designating $H$. fidelis as the type species of Boriomyia, Killington proposed the name Kimminsia for the British species formerly included in Boriomyia, the remaining non-British species of the former Boriomyia (other than B. speciosa) presumably being also referable to this genus. A Palaearctic species, $H$. betulina Strøm was selected as the type of Kimminsia. These two genera were considered to be separated by venational features which had already been noted by Banks. These views were reiterated by Killington in 1937b. Tjeder (I94I) in a critique of Killington's work and without specimens of $B$. fidelis to study felt that the venational distinctions which had been drawn between Boriomyia and Kimminsia were not sufficient to warrant generic separation. Subsequently in a long series of papers (1943a, 1943b, 1944, 1945, 1951, 1953a, 1953b, 1954, 1955, 1960), he has continued to use the name Boriomyia to cover the Kimminsia group of species. 
Circumstances have thus conspired to make it seem that Kimminsia is a taxonomic segregate from the closely allied genus Boriomyia and that the question of whether to recognize one genus or two simply depends on the emphasis which one places on the differences in the venation of these two groups. Actually this is misleading, for as long ago as 1940 Carpenter pointed out that the differences between these two genera are much more far-reaching than had been suspected, involving not only consistent differences in venation, but fundamental differences in the basic organization of the genitalia of both sexes. Indeed, it was Carpenter's contention that the true affinities of Boriomyia lie not with Kimminsia at all, but rather with the genus $M e$ galomus.

The findings of the present study lend complete support to this view. Details of the biology of the Palaearctic Megalomus hirtus (Linné) including several excellent figures of the larvae have been published by Killington ( 1934, 1937a), while the present author has reared the immature stages of an unidentified species of Megalomus from Mexico. In addition, modern figures and descriptions of larvae of species of Kimminsia, Wesmaelius, Psectra, Sympherobius, Hemerobius, Micromus, and Drepanepteryx have also been provided by Smith (1923, 1934), Killington (1936, 1937a, 1946) and Fulmek ( I94I) and as the writer has been able to rear or study larvae of species of the last four of these genera, detailed comparisons of a variety of larval types of the Hemerobiidae have been possible.

Only in very general features shared by the larvae of all known hemerobiids do those larvae of Micromus, Hemerobius, Wesmaelius and Kimminsia which are known bear any close structural resemblance to the larvae of the remaining groups and they will not be discussed further. A series of striking similarities is to be found in the larvae of Boriomyia and Megalomus involving the shape of the labial palpi, the form of the terminal segment of the antenna and in the appearance of the mature larva. The swollen, inflated shape of the labial palpi, particularly striking in the first instar larvae, but noticeable in the later two instars as well, is present only in Sympherobius and Psectra in addition to Megalomus and Boriomyia although it has never been observed to reach the extreme degree in the first two of these genera that it does in the latter two. The extremely shortened terminal segment of the antenna, surmounted by an apical seta nearly as long as or longer than this segment, is known to the writer only in Boriomyia and Megalomus. A much less drastic reduction in the terminal segment occurs in Sympherobius, but here the segment is somewhat flask- 
shaped as it is dilated basally and the terminal seta is much shorter than the length of the segment. The swollen, physogastric appearance of the mature larva has probably been produced several times independently in the Hemerobiidae in correlation with a more sessile mode of larval life. The condition has been approached in Sympherobius, Psectra and Drepanepteryx although in no species of these groups known to the writer does it reach the extreme which has been produced in Boriomyia and Megalomus. Associated with this inflated, sessile larva is the habit of carrying the head deeply retracted within the prothorax, developed to an extreme degree in Boriomyia, Megalomus, and Drepaneptaryx, and the supression of the latero-dorsal sclerites of the thoracic segments. In Sympherobius, Psectra and Drepanepteryx these sclerites have been strongly reduced on the meso- and metathorax, but those of the prothorax have remained relatively large and prominent. In Boriomyia and Megalomus alone have the prothoracic latero-dorsal sclerites been reduced to the point where they are difficult to demonstrate. Killington states that these sclerites are lacking on the prothorax of $\boldsymbol{M}$. hirtus although it seems possible that close scrutiny might reveal their presence since their remnants can just be detected in B. fidelis as well as the Mexican species of Megalomus studied by the writer. One additional point of resemblance between members of Boriomyia and Megalomus is to be found in the peculiar rest position of the adult noted above for $B$. fidelis, which was observed by the writer in adults of the Mexican species of Megalomus studied, and noted by Killington (1937a) in M. hirtus.

The writer has presented the evidence for the relationship of Boriomyia and Megalomus to Mr. Tjeder who, it has been noted, previously felt that there were insufficient characters to separate Kimminsia from Boriomyia. In addition, specimens of $B$. fidelis were supplied for his study. Mr. Tjeder has informed the writer (in litt.) that he is now in full agreement with the placement of $B$. fidelis near Megalomus (indeed, he feels that this species must be placed in Megalomus). He has, however, continued to use the name Boriomyia for the Kimminsia species (Tjeder, 1960), arguing (in litt.) that Banks' genotype designation for Boriomyia in 1905 must be considered valid. The writer is of the opinion that the Rules are perfectly clear on this point and that the validation of Banks' designation would require an action of the International Commission to set aside the Rules. It should be noted that in addition to Killington (1937a, I937b) and Carpenter (1940), Fraser (1940, 1942, 1959), Friedrich (1953), 
Nakahara (1956, 1960) and Parfin (1956) have used the names Boriomyia and Kimminsia in the sense adopted in the present paper.

Concerning the question of the validity of Boriomyia as a genus distinct from Megalomus, this must await a study of the type species of Megalomus, the Palaearctic M. tortricoides Rambur, as well as a wider variety of species of this genus than has been available to the present writer. Carpenter ( I940) was able to separate these genera on the basis of the position of the radial cross vein with reference to the point of origin of $\mathrm{R}_{5}$ in the hindwing, although he felt that species which were intermediate in this character would probably be found. Recently Nakahara (1960) has observed that B. fidelis possesses a median lobe of the fused parameres of the male genitalia (present also in B. speciosa) which is said to be lacking in species of Megalomus. A second character of $B$. fidelis considered by Nakahara to be of generic importance, the basally fused and apically bifucrate "aedeagus", is present also in at least the Nearctic species $M$. minor Banks which is a Megalomus by the criterion of a lack of the median lobe of the fused parameres.

It is the opinion of the present writer that stable generic limits in the Hemerobiidae usually involve greater differences in the basic ground plan of the male genitalia than those aduced by Nakahara, and frequently correlate with differences in the structure of one or more of the immature stages and in constant venational features as well. In these respects, Boriomyia seems poorly distinct from Megalo$m u s$ and will probably fall as a synonym of this genus.

\section{Literature Cited}

BANKs, N. 1904. A list of the neuropteroid insects, exclusive of Odonata, from the vicinity of Washington, D.C. Proc. Ent. Soc. Wash. 6:201-217. Ent. Soc. $32: 21-51$. 1905. A revision of the Nearctic Hemerobiidae. Trans. Amer. $37: 223-233$.

1930. New neuropteroid insects from the United States. Psyche

1935. A few new North American Neuroptera. Psyche 42:53-57.

Carpenter, F. 1940. A revision of the Nearctic Hemerobiidae, Berothidae, Sisyridae, Polystoechotidae and Dilaridae (Neuroptera). Proc. American Acad. Arts Sci. $74: 193-280$.

FRASER, F. 1940. Kimminsia rava (Withy.) in Hampshire. Entomologist 73 : 166.

1942. A new species of Kimminsia (Neur., Hemerobiidae), with historical figures and notes. Ent. Monthly Mag. $78: 80-86$.

1959. Mecoptera, Megaloptera and Neuroptera. Handbooks for the Identification of British Insects 1 (12-13):1-40. London: Royal Ent. Soc. London.

FRIEDRICH, H. 1953. Neuroptera. Bronns Klassen und Ordnungen des Tierreichs. Funfter Band, 3. Abteilung, XII. Buch, Teil a. Leipzig: Akademische Verlagsgesellschaft Geest \& Portig K.-G. pp. 1-148. 
Fülmek, L. 1941. Über die Aufzucht von Drepanepteryx phalaenoides L. ex ovo. (Neuroptera: Planipennia, Hemerobiidae). Arbeiten über Morphology und taxonomische Entomologie aus Berlin-Dahlem 8:127-130.

Killington, F. 1934. On the life-histories of some British Hemerobiidae. Trans. Soc. British Ent. $1: 119-134$.

1936. A monograph of the British Neuroptera. Volume I. London: The Ray Society. pp. 1-269 + i-xix.

1937a. A monograph of the British Neuroptera. Volume II.

London: The Ray Society. pp. 1-306 + i-xii.

1937b. The generic names of the British Neuroptera, with a check list of the British species. The Generic Names of British Insects $4: 60-80$. London: Royal Ent. Soc. London.

1946. On Psectra diptera (Burm.) (Neur., Hemerobiidae), including an account of its life history. Ent. Monthly Mag. 82:161-176.

Nakahara, W. 1956. New or little known Neuroptera from Japan and adjacent Territories (Neuroptera). Kontyû 24:182-191.

Mushi 34:1-69.

1960. Systematic studies on the Hemerobiidae (Neuroptera).

Parfin, S. 1956. Taxonomic notes on Kimminsia (Neuroptera: Hemerobiidae). Proc. Ent. Soc. Wash. $58: 203-209$.

Peterson, A. 1953. A manual of entomological techniques. Ann Arbor, Michigan: J. W. Edwards. pp. 1-367 + i-v.

Smith, R. 1922. The biology of the Chrysopidae. Cornell Univ. Agric. Expt. Sta. Memoir 58:1287-1372.

1923. The life histories and stages of some hemerobiids and allied species. Ann. Ent. Soc. Amer. 16:129-148.

1934. Notes on the Neuroptera and Mecoptera of Kansas, with keys for the identification of species. Jour. Kansas Ent. Soc. 7:120-144.

TJEDER, B. 1941. Some remarks on "The generic names of the British Neuroptera". Ent. Tid. $62: 24-31$.

1943a. The Neuroptera and Mecoptera of Northern Norway (Nordland, Troms and Finnmark). Troms $\phi$ Museums Arshefter, Naturhistorisk Avd. Nr. 25. Vol. 63 (1940):1-15.

1943b. Revision of the Norwegian Neuroptera and Mecoptera. Norsk Ent. Tid. 6:133-139.

1944. Norwegian Neuroptera and Mecoptera in the Bergen Mu-

seum. Bergens Museums Årbok, Naturvitenskapelig rekke Nr. 1:1-11. 1945. Catalogus Neuropterorum et Mecopterorum Norvegiae.

Norsk Ent. Tid. $7: 93-98$.

1951. The mountain fauna of the Virihaure area in Swedish

Lapland. Neuroptera. K. Fysiogr. Sällsk. Lund Handl. N. F. 61:121.

227-228. 1953a. Faunistical notes on Swedish Neuroptera. Opus. Ent. 18 :

I-X. Opus. Ent. $18: 71$

1954. Genital structures and terminology in the order Neurop-

tera. Ent. Medd. $27: 23-40$.

1955. Two new species of Boriomyia from South Africa. Annals

South African Mus. 51:381-385.

Opus. Ent. 25 :146-149. 

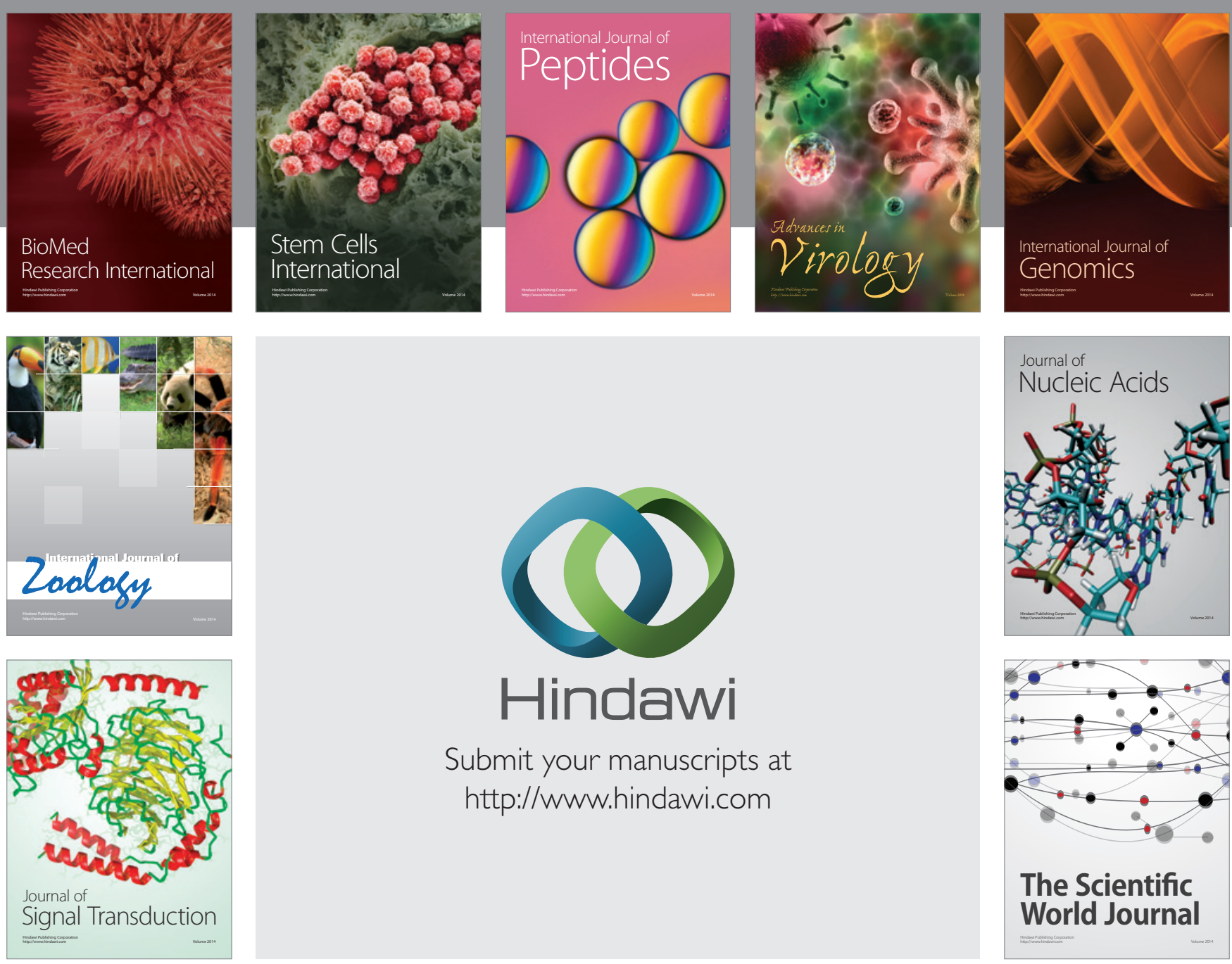

Submit your manuscripts at

http://www.hindawi.com
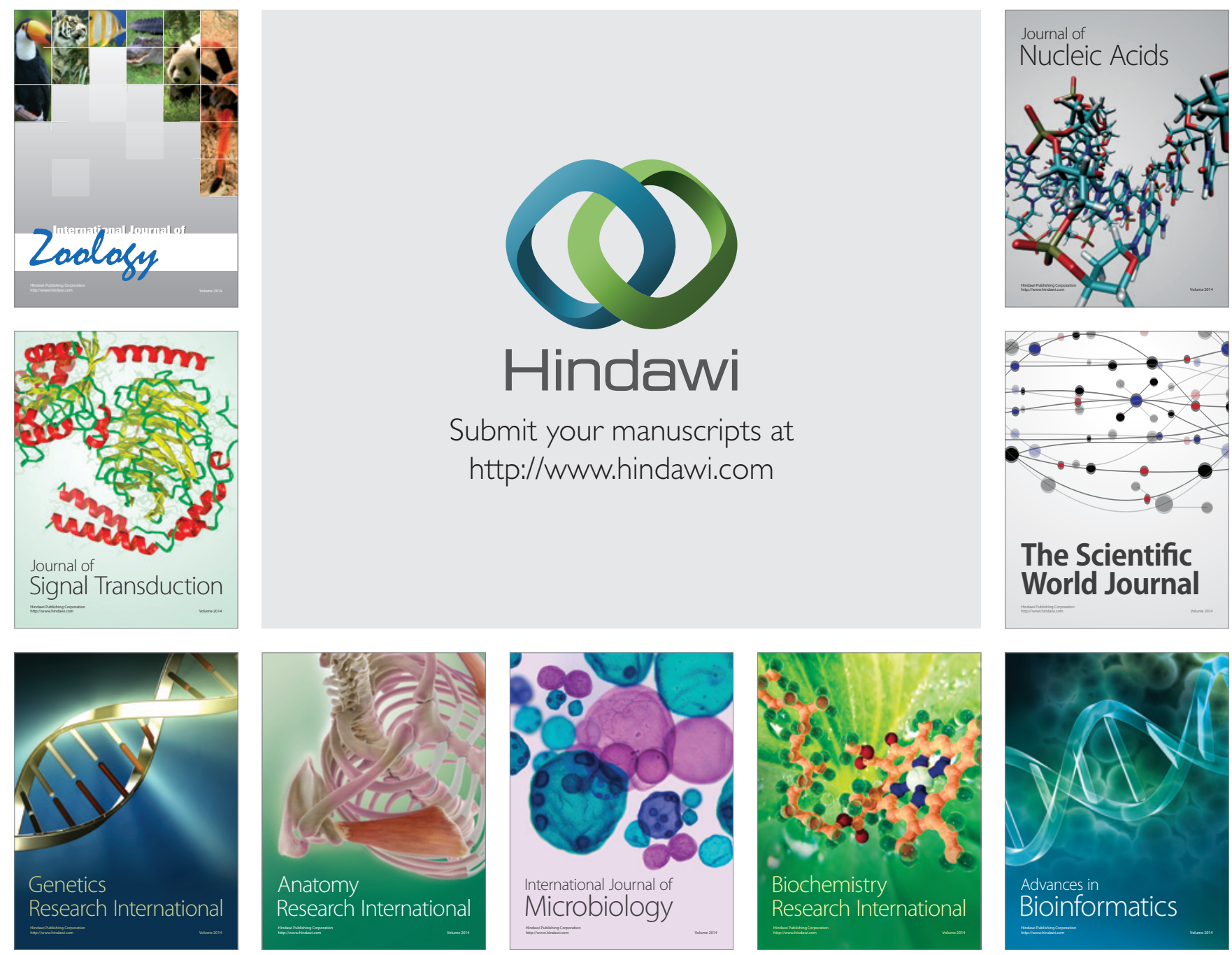

The Scientific World Journal
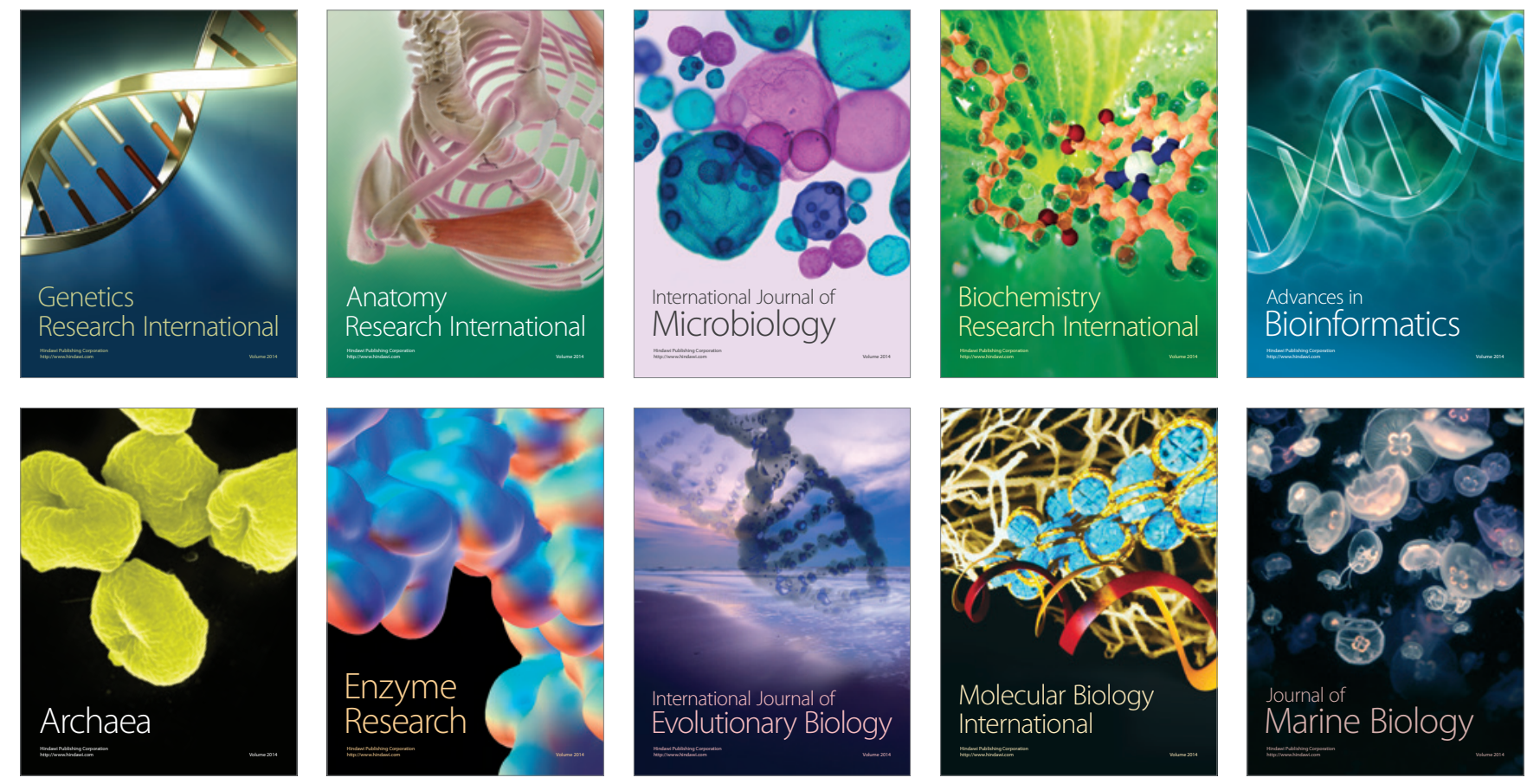